\title{
Uma Análise SWOT do ConteXto CTSS das Atividades LABORATORIAIS DO ENSINO SECUNDÁRIO
}

\author{
Dominique A. Costa ${ }^{1}$, M. Gabriela T. C. Ribeiro ${ }^{1, *}$ \\ e AdÉlIO A. S. C. MACHADO²
}

\begin{abstract}
$A_{p}$ A presenta-se uma metodologia, baseada na análise SWOT, para avaliar atividades laboratoriais com vista a aferir 0 seu enquadramento na perspetiva Ciência-Tecnologia-Sociedade-Sustentabilidade (CTSS). A ferramenta foi usada na avaliação das atividades laboratoriais propostas nos programas em vigor dos $10^{\circ}$ e $11^{\circ}$ anos, tendo-se concluído que a adoção de um enquadramento CTSS, como presentemente se impõe para os laboratórios de ensino, exigirá a elaboração e desenho de novas experiências e profundas alterações dos programas atuais.
\end{abstract}

O movimento CTS, "Ciência-Tecnologia-Sociedade", prescreve que o ensino da ciência e tecnologia deva atender ao contexto cultural, social, económico e político em que as atividades de ciência e tecnologia são desenvolvidas, com vista a proporcionar aos estudantes formação que Ihes permita compreender o impacto da ciência e tecnologia no mundo real, na vida diária e na sociedade, e serem capazes de tomar decisões responsáveis sobre as variadas questões que, como cidadãos e/ou profissionais, Ihes serão postas ao longo da vida nestes campos [1]

O conhecimento científico e tecnológico permitiu à Sociedade desenvolver, a partir dos anos sessenta do século $X X$, com a emersão do moderno Ambientalismo, uma atitude a favor da conservação do Ambiente. Neste contexto, o movimento CTS incorporou uma componente ambiental quase logo desde o seu lançamento e, ocasionalmente, mas nem sempre, foi-Ihe acrescentado o A de "Ambiente" e passou a CTSA, "Ciência, Tecnologia, Sociedade e Ambiente", pelo que as duas designações e siglas tendem a ser usadas indiferenciadamente, como referido numa recente revisão da respetiva literatura [2].

$\mathrm{Na}$ situação atual, em que decorre a década da Educação para o De-

REQUIMTE, Departamento de Química e Bioquímica da Faculdade de Ciências da Universidade do Porto, R. Campo Alegre, 687, 4169--007 Porto

Departamento de Química e Bioquímica da Faculdade

de Ciências da Universidade do Porto, R. Campo

Alegre, 687, 4169-007 Porto

*E-mail: gribeiro@fc.up.pt senvolvimento Sustentável (EDS) da UNESCO (2004-2015) [3] e é cada vez mais importante que a Tecnologia evolua no sentido de contribuir para este [4], do qual é um ingrediente fulcral, a postura CTS/CTSA deve adquirir explicitamente esta componente e evoluir para Ciência-Tecnologia-Sociedade-Sustentabilidade - o que pede uma sigla alternativa mais adequada, CTSS ou, em estilo de fórmula química, $\mathrm{CTS}_{2}$. Esta perspetiva para o ensino científico-tecnológico dá adequada relevância à Sustentabilidade, que tem de ser conquistada mediante contribuições inovatórias de dois tipos: por um lado resultantes, quer da Ciência, quer da Tecnologia, que permitam a implementação da Engenharia da Sustentabilidade; por outro, de reorganização da Sociedade, mediante alterações do comportamento humano, individual e coletivo, a que os cientistas e tecnólogos devem estar atentos porque podem ser potenciados pelo progresso tecnológico. Em suma, o enquadramento do ensino científico-tecnológico no paradigma da Sustentabilidade pressiona que passe a ser feito na postura CTSS.

No caso particular da Química, como os produtos químicos são imprescindíveis para obter qualidade de vida e a sua produção tem de aumentar para eliminar a pobreza química [5], tem de evoluir no sentido de a Química Industrial se integrar no Desenvolvimento Sustentável e poder contribuir para este. A evolução requerida significa produzir maiores quantidades de produtos químicos, mas simultaneamente propiciar menos poluição, resíduos, etc., e consumir menos recursos naturais (energia e materiais) - este é o objetivo da Química Verde. Para que o ensino desta possibilite aos alunos uma melhor integração no paradigma da Sustentabilidade, em face do que foi dito acima, parece natural que seja feito no quadro da CTSS.

Os atuais programas para o ensino da Física e da Química no ensino Secundário referem, na sua apresentação, a opção pela "educação CTS" [6]. Por outro lado, uma análise da verdura das atividades laboratoriais propostas nos programas de Química do ensino secundário realizada anteriormente $[7,8]$, evidenciou que a maior parte das respetivas experiências apresentam uma verdura limitada e que uma fração considerável delas apresenta riscos elevados devido ao uso de substâncias perigosas (cerca de 30\% das substância usadas). Estes factos levantam a questão de averiguar até que ponto os programas se integram na postura CTSS, um contexto mais atual que CTS. Assim, na sequência do trabalho anterior sobre as atividades laboratoriais nos currículos do secundário [7, 8], decidiu fazer-se incidir esta avaliação sobre estas atividades. A análise deste objetivo permitiu identificar desde logo duas questões fundamentais sobre a avaliação (e o desenho) de experiências laboratoriais: (i) que critérios devem estas atividades cumprir para serem adequadas a um ensino CTSS?; e (ii) que metodologia pode ser usada para proceder a essa avaliação? Note-se que estas questões são gerais e não apenas válidas para atividades experimentais. 
O objetivo deste artigo é apresentar uma tentativa de resposta a estas questões, mais precisamente, propor um conjunto de critérios e uma metodologia (com base na análise SWOT) para avaliar o cumprimento desses critérios que, no seu conjunto, constituem um instrumento para avaliar se as atividades laboratoriais estão desenhadas de forma a se adequarem a um ensino CTSS. O instrumento foi testado com as atividades dos atuais programas de química dos $10^{\circ}$ e $11^{\circ}$ anos do ensino secundário.

\section{DesenVolvimento do InStRUMENTO de Avaliação}

Na Fgura 1 apresenta-se tentativamente um conjunto de aspetos (formam uma rede) que interrelacionam a Química, a Tecnologia, a Sociedade e a Sustentabilidade, e que serviram de base para a escolha dos critérios a estabelecer na avaliação. Para avaliar o cumprimento dos critérios, e atendendo a que se pretende uma avaliação qualitativa, já que os aspetos a considerar são de natureza diversa e, na sua maioria, dificilmente ou não quantificáveis, usou-se a análise SWOT, que pareceu adequada para o efeito [9].

Análise SWOT. A análise SWOT foi criada na Harvard Business School nos anos sessenta e, embora tenha sido originalmente utilizada na avaliação empresarial, é aplicada atualmente nas mais diversas áreas, tendo sido ultimamente empregue na área da química [10] e da tecnologia [11]. O termo SWOT resulta das iniciais $S$ (Strenghs - pontos fortes), W (Weaknesses - pontos fracos), O (Opportunities - oportunidades) e T (Threats - ameaças). Os pontos fortes indicam os aspetos positivos, e os fracos os negativos, relativamente aos objetivos a atingir; o seu conjunto corresponde à análise interna, já que os aspetos considerados são atributos do objeto. As oportunidades podem tornar mais forte o objeto em análise e as ameaças pôr em causa o seu sucesso; o seu conjunto corresponde à análise externa, já que resultam de fatores externos ao objeto. Após definidos os objetivos, identificam-se os pontos fortes e fracos, bem como as oportunidades e ameaças que se colocam ao cumprimento desses objetivos. Os resultados são apresentados em quadros, designados matrizes SWOT, constituídos por quatro subquadros, cada um dizendo respeito a uma das quatro características do SWOT (ver exemplos adiante).

No presente caso, os objetos em análise são as atividades laboratoriais e o objetivo é estas serem adequadas a um ensino CTSS. Para a análise, é necessário definir os critérios a que devem obedecer as atividades laboratoriais para cumprirem este objetivo e que constituem as dimensões de análise relativamente às análises interna e externa.

Análise interna. Para esta análise, tomando em consideração as ligações mais importantes da Ciência, neste caso a Química, com a Tecnologia, a Sociedade e a Sustentabilidade, estabelecidas na Figura 1, foram escolhidas as chamadas dimensões de análise (os aspetos mais importantes para a caracterização dos pontos fortes e fracos no cumprimento do objetivo definido). Por meio de um processo que se descreve adiante (ver secção "Construção da ferramenta e análise SWOT"), foram identificadas vinte dimensões que se apresentam na Tabela 1.

Atendendo a que neste trabalho se consideram os laboratórios existentes nas escolas secundárias, classifica-se em "equipamento" os equipamentos de laboratório menos vulgares, tais como: centrífuga, evaporador rotativo, bomba de vácuo, estufa, mantas, banho termostatizado, etc. (riscos contabilizados na dimensão 4). As placas de aquecimento, banhos de água, parafina, fogões "camping gás", termómetros, material de vidro diverso, etc., são

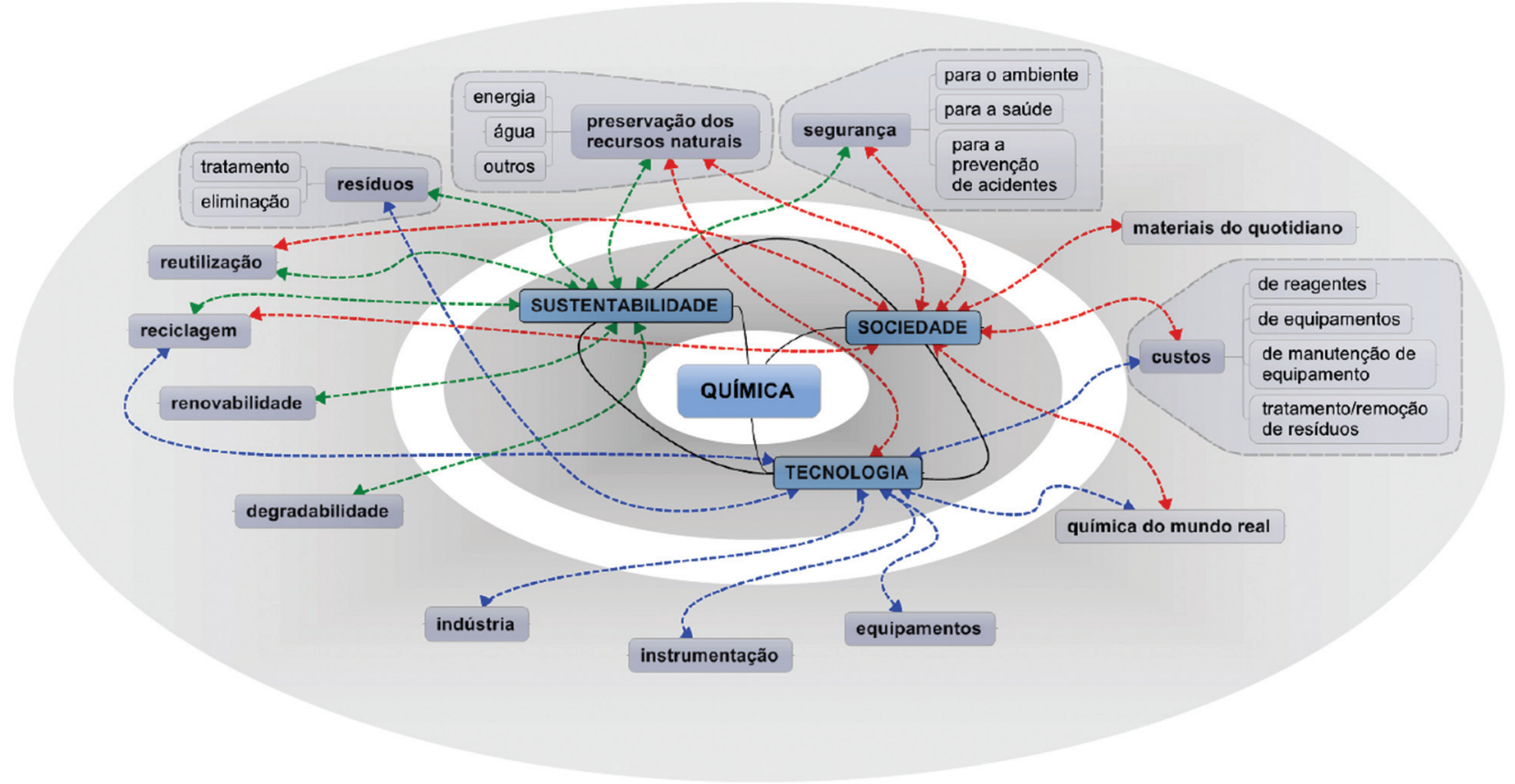

Figura 1 - Rede Química-Tecnologia-Sociedade-Sustentabilidade para elaboração de critérios usados na avaliação 
Tabela 1 - Critérios para a contabilização dos pontos fortes e fracos

\begin{tabular}{|c|c|c|c|}
\hline \multicolumn{2}{|c|}{ Dimensões de análise } & \multirow{2}{*}{$\begin{array}{l}\text { Ponto Forte } \\
\begin{array}{l}\text { No caso de substâncias (Xi, Xn ou } \\
\text { sem indicação de riscos) }\end{array}\end{array}$} & \multirow{2}{*}{$\begin{array}{c}\text { Ponto Fraco } \\
\text { No caso de substâncias }\left(T, T^{+}, C\right)\end{array}$} \\
\hline $\begin{array}{l}\text { Riscos para a saúde (devido às } \\
\text { substâncias envolvidas) }\end{array}$ & $\begin{array}{l}\text { 1. Riscos para a saúde devido a } \\
\text { todas as substâncias envolvidas: } \\
\text { reagentes, produtos, resíduos, } \\
\text { solventes, substâncias auxiliares } \\
\text { (como por ex. as utilizadas nos } \\
\text { banhos de aquecimento e na } \\
\text { instrumentação) }\end{array}$ & & \\
\hline $\begin{array}{l}\text { Riscos para o ambiente (devido às } \\
\text { substâncias envolvidas) }\end{array}$ & $\begin{array}{l}\text { 2. Riscos para o ambiente devido } \\
\text { a todas as substâncias envolvidas: } \\
\text { reagentes, produtos, resíduos, } \\
\text { solventes, substâncias auxiliares } \\
\text { (como por ex. as utilizadas nos } \\
\text { banhos de aquecimento e na } \\
\text { instrumentação) }\end{array}$ & $\begin{array}{l}\text { No caso de substâncias sem } \\
\text { indicação de riscos para o } \\
\text { ambiente }\end{array}$ & No caso de substâncias (N) \\
\hline \multirow{5}{*}{$\begin{array}{l}\text { Riscos de acidente (devido } \\
\text { às substâncias envolvidas, } \\
\text { equipamentos, instrumentação, } \\
\text { montagens e outros materiais } \\
\text { vulgares de laboratório) }\end{array}$} & $\begin{array}{l}\text { 3. Riscos de acidente devido às } \\
\text { substâncias envolvidas }\end{array}$ & $\begin{array}{l}\text { No caso de substâncias (Xi, Xn ou } \\
\text { sem indicaçãa de riscos) }\end{array}$ & $\begin{array}{l}\text { No caso de substâncias }\left(T, T^{+}, C, O \text {, }\right. \\
\left.F, F^{+}\right)\end{array}$ \\
\hline & $\begin{array}{l}\text { 4. Riscos de acidente devido ao } \\
\text { equipamento }\end{array}$ & Com riscos baixos ou moderados & Com riscos elevados \\
\hline & $\begin{array}{l}\text { 5. Riscos de acidente devido à ins- } \\
\text { trumentação }{ }^{1}\end{array}$ & Com riscos baixos ou moderados & Com riscos elevados \\
\hline & $\begin{array}{l}\text { 6. Riscos de acidente devido a } \\
\text { montagens }^{1}\end{array}$ & Com riscos baixos ou moderados & Com riscos elevados \\
\hline & $\begin{array}{l}\text { 7. Riscos de acidente devido a ou- } \\
\text { tros materiais vulgares de labora- } \\
\text { tório }\end{array}$ & Com riscos baixos ou moderados & Com riscos elevados \\
\hline \multirow[t]{2}{*}{$\begin{array}{l}\text { Consumo de água como solvente } \\
\text { ou reagente e como facilidade }\end{array}$} & $\begin{array}{l}\text { 8. Consumo de água como solven- } \\
\text { te ou reagente }\end{array}$ & Com consumo baixo $(\mathrm{V} \leq 50 \mathrm{~mL})$ & Com consumo elevado ( $\mathrm{V}>50 \mathrm{~mL}$ ) \\
\hline & $\begin{array}{l}\text { 9. Consumo de água como facili- } \\
\text { dade (ex. água de refrigeração, de } \\
\text { banhos, etc.) }\end{array}$ & Com consumo baixo ( $\mathrm{V} \leq 200 \mathrm{~mL})$ & $\begin{array}{l}\text { Com consumo elevado ( } \mathrm{V}>200 \\
\mathrm{~mL} \text { ) }\end{array}$ \\
\hline Consumo de outros solventes & $\begin{array}{l}\text { 10. Consumo de solventes para } \\
\text { além da água }\end{array}$ & Com consumo baixo $(\mathrm{V} \leq 50 \mathrm{~mL})$ & Com consumo elevado $(\mathrm{V}>50 \mathrm{~mL})$ \\
\hline \multirow{2}{*}{$\begin{array}{lrr}\text { Utilização } & \text { de } & \text { substâncias } \\
\text { renováveis e/ou } & \text { degradáveis a } \\
\text { produtos inócuos } & \end{array}$} & $\begin{array}{l}\text { 11. Utilização de substâncias reno- } \\
\text { váveis (a água não é contabilizada) }\end{array}$ & Utilizam-se & Não se utilizam \\
\hline & $\begin{array}{l}\text { 12. Utilização de substâncias de- } \\
\text { gradáveis a produtos inócuos (a } \\
\text { água não é contabilizada) }\end{array}$ & Utilizam-se & Não se utilizam \\
\hline Consumo energético & 13. Consumo energético & $\begin{array}{l}\text { Se a experiência se realiza à } \\
\text { temperatura ambiente }\end{array}$ & $\begin{array}{l}\text { Se é necessário aquecer ou } \\
\text { arrefecer }\end{array}$ \\
\hline \multirow{2}{*}{ 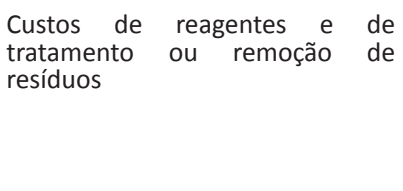 } & 14. Custo dos reagentes & $\begin{array}{l}\text { Custo baixo por reagente }(\leq 0,05 \\
€ / \mathrm{g} \text { ou } \leq 0,05 € / \mathrm{mL})\end{array}$ & $\begin{array}{l}\text { Custo elevado por reagente }(>0,05 \\
€ / \mathrm{g} \text { ou }>0,05 € / \mathrm{mL})\end{array}$ \\
\hline & $\begin{array}{l}\text { 15. Custos de tratamento ou remo- } \\
\text { ção de resíduos }\end{array}$ & $\begin{array}{l}\text { Não existem para resíduos } \\
\text { sem indicação de riscos para o } \\
\text { ambiente }\end{array}$ & $\begin{array}{l}\text { Existem para resíduos com riscos } \\
\text { para o ambiente }(\mathrm{N})\end{array}$ \\
\hline $\begin{array}{l}\text { Utilização de materiais do } \\
\text { quotidiano }\end{array}$ & $\begin{array}{l}\text { 16. Utilização de materiais do quo- } \\
\text { tidiano (a água não é contabilizada) }\end{array}$ & Utilizam-se & Não se utilizam \\
\hline \multirow{2}{*}{$\begin{array}{l}\text { Relação com a química do mundo } \\
\text { real, química industrial e/ou com } \\
\text { outras situações }\end{array}$} & $\begin{array}{l}\text { 17. Relação com a química indus- } \\
\text { trial }\end{array}$ & Relacionada & Não relacionada \\
\hline & $\begin{array}{l}\text { 18. Relação com outras situaç̃ões } \\
\text { da química do mundo real (ex. saú- } \\
\text { de, agricultura, transportes, etc.) }\end{array}$ & Relacionada & Não relacionada \\
\hline \multirow{2}{*}{$\begin{array}{l}\text { Utilização de equipamentos e } \\
\text { instrumentação }\end{array}$} & 19. Utilização de equipamentos & Utilizam-se & Não se utilizam \\
\hline & 20. Utilização de instrumentação & Utilizam-se & Não se utilizam \\
\hline
\end{tabular}

1 Só se consideram se existirem equipamentos e/ou instrumentação e/ou montagens e/ou outros materiais vulgares de laboratório

2 Considera-se que a utilização de material de vidro envolve riscos baixos e que os banhos de aquecimento ou fogões "camping gás" envolvem riscos elevados 
considerados materiais vulgares (não são contabilizados na rubrica "equipamento") - os respetivos riscos são contabilizados na dimensão 7. Classificam-se numa nova rubrica, "instrumentação", os equipamentos de medição e análise, tais como: espectrofotómetro, medidor de $\mathrm{pH}$, aparelhos de determinação dos pontos de fusão e de ebulição, espectroscópio, etc. (riscos contabilizados na dimensão 5). Por "montagens" entende-se material de vidro e/ou equipamentos e/ ou instrumentação quando acoplados (riscos contabilizados na dimensão $6)$. Só se contabilizam aqui os riscos devido às condições em que as experiências se desenvolvem (por exemplo riscos de implosão ou explosão), já que os riscos devido à utilização de equipamentos ou instrumentação que envolvam riscos ou de outros equipamentos e materiais vulgares no laboratório, não contabilizados em "equipamentos", e que também envolvam riscos, são contabilizados em 4, 5 e 7, respetivamente. Considera-se que a utilização, por si só, de material de vidro, como balões, gobelés, matrazes, pipetas, termómetros, etc., envolve riscos baixos. A química do mundo real engloba a indústria química $\mathrm{e}$ variadas áreas de utilização de pro- dutos químicos ou onde a química é relevante, como a saúde, a agricultura, os transportes, etc. A indústria química é aqui considerada independentemente das outras situações da química do mundo real, atendendo à sua relevância para a química. Não são consideradas outras facilidades para além da água (porque são usadas em menores quantidades), a não ser que envolvam riscos e, nesse caso, são contempladas como substâncias.

Quando as experiências não envolvem reações químicas, os critérios podem requerer adaptação.

Análise externa. Para o estabelecimento das dimensões, no que se refere às oportunidades, tomaram-se em consideração aspetos que podem levar ao melhoramento das atividades, diminuindo o impacto dos pontos fracos atrás referidos; no que se refere às ameaças, condicionamentos externos que possam criar dificuldades à sua utilização e impliquem o redesenho das atividades ou o seu abandono. Assim, foram definidas cinco dimensões de análise relativamente às oportunidades e quatro relativamente às ameaças que se colocam à sua realização, apresentadas na Tabela 2.
Construção da ferramenta e análise SWOT. A análise SWOT foi aplicada à totalidade das atividades experimentais propostas nos programas de química em vigor, dos $10^{\circ}$ e $11^{\circ}$ anos do ensino secundário, constituídas por oitenta e seis experiências, no conjunto dos dois anos (Tabela 3).

Na construção da ferramenta SWOT para esta finalidade, as dimensões de análise (Tabela 1) não estavam todas definidas à partida, mas resultaram do processo de análise que decorreu da seguinte forma: (1) para cada experiência foram identificados os pontos fortes e fracos, oportunidades e ameaças relativas às dimensões de análise definidas à partida e construída a respetiva matriz SWOT; (2) para cada dimensão de análise foram identificadas as experiências com os mesmos pontos fortes, constituindo uma mesma categoria de análise (o mesmo para os pontos fracos, ameaças e oportunidades); (3) à medida que a análise decorria, as experiências, agrupadas numa mesma categoria, eram constantemente comparadas entre si, com o objetivo de conseguir consistência interna dentro de cada categoria, o que implicou, por vezes, a criação de novas dimensões de análi-

Tabela 2 - Oportunidades e ameaças - aspetos a considerar nas dimensões de análise

\begin{tabular}{|c|c|}
\hline \multicolumn{2}{|c|}{ OPORTUNIDADES } \\
\hline Dimensões de análise & Implicações \\
\hline Realização à microescala & $\begin{array}{l}\text { Redução dos riscos e custo dos reagentes, bem como tratamento ou } \\
\text { remoção de resíduos, pois são em menor quantidade }\end{array}$ \\
\hline Reutilização e reciclagem de materiais & Utilização de materiais reciclados ou produtos de outras atividades \\
\hline Redução ou reutilização de água & $\begin{array}{l}\text { Alteração de procedimentos de modo a baixar o consumo de água e/ou } \\
\text { reutilizar a água, nomeadamente a água de refrigeração nas destilações }\end{array}$ \\
\hline Substituição de reagentes ou solventes por outros mais vantajosos & $\begin{array}{l}\text { Substituição por reagentes com riscos mais baixos, renováveis, } \\
\text { degradáveis em produtos de baixo risco para o ambiente, de baixo } \\
\text { custo e do quotidiano }\end{array}$ \\
\hline Possibilidade de baixar a intensidade de energia & $\begin{array}{l}\text { Alteração de procedimentos de modo a aumentar a eficiência } \\
\text { energética }\end{array}$ \\
\hline \multicolumn{2}{|c|}{ AMEAÇAS } \\
\hline Dimensões de análise & Implicações \\
\hline Imposição externa de mais segurança & $\begin{array}{l}\text { Aumento dos custos de tratamento ou remoção de resíduos, ou de } \\
\text { melhoramento das condições dos laboratórios, ou de abandono das } \\
\text { experiências }\end{array}$ \\
\hline Hottes insuficientes nas escolas & Aumento de custos para melhorar condições do laboratório \\
\hline Verbas limitadas & $\begin{array}{l}\text { Dificuldades se a experiência implicar custos elevados (reagentes, } \\
\text { equipamentos, instrumentação, tratamento ou remoção de resíduos, } \\
\text { melhoramento das condições dos laboratórios) }\end{array}$ \\
\hline Imposição externa para reduzir consumos de água e/ou de energia & Reutilização da água e experiências a pressão e temperatura ambientais \\
\hline
\end{tabular}


se que permitissem discriminar as experiências (por exemplo, a criação de diversas dimensões relativas aos riscos de acidente, 3-7); (4) finalmente, quando a análise deixou de fornecer novas informações relevantes para a análise, considerou-se a categoria saturada e o processo terminado [12].

Após a análise terminada verificou-se que as dimensões de análise 4-6 e 10 apareciam nos pontos fortes, mas não nos pontos fracos. A dimensão 4 (risco de acidente devido ao equipamento) aparece só como ponto forte, porque se usa um único equipamento (manta) que foi considerado de baixo risco; o mesmo sucede para a dimensão 5 (risco devido à instrumentação), onde só se utiliza o medidor de pH eletrónico e o espectroscópio, ambos considerados de baixo risco, para a dimensão 6 (riscos devido à montagem), só presente nas destilações consideradas também de baixo risco, e para a dimensão 10 (consumo de solventes para além da água), em que os solventes utilizados são o etanol e hexano, ambos com consumos considerados baixos. Estas dimensões poderiam ser eliminadas na análise, atendendo a que não existem riscos efetivos, mas optou-se por mantê-las para permitir estabelecer um instrumento de aplicação mais geral, que permita maior discriminação na análise.
Para ilustrar a utilização de diversas dimensões de análise e o formato do resultado da análise para cada experiência, apresentam-se as análises de quatro experiências dos $10^{\circ}$ e $11^{\circ}$ anos (duas de cada ano) nas Tabelas 4 e 5 (matrizes SWOT), respetivamente. Para estes exemplos foram escolhidas experiências que exemplificassem vários tipos de situações encontradas, pertencessem a ambos os anos avaliados e que, no seu conjunto, apresentassem pontos fortes para quase todas as dimensões de análise. São discutidas brevemente duas destas matrizes, uma de cada ano, para exemplificação do procedimento.

Tabela 3 - Experiências avaliadas

\begin{tabular}{|c|c|}
\hline Experiência & $\begin{array}{l}\text { Designação das experiências } \\
10 \% \text { ano }\end{array}$ \\
\hline 1 & Separar os componentes de uma mistura de água, sal e solo \\
\hline 2 & Separar uma mistura de óleo ou azeite e água \\
\hline 3 & Separar uma mistura de hexano e água \\
\hline 4 & Dessalinizar água do mar ou água salgada \\
\hline 5 & Separar água e acetona de uma mistura \\
\hline 6 & Análise elementar do cloreto de sódio por via seca \\
\hline 7 & Análise elementar do cloreto de bário por via seca \\
\hline 8 & Análise elementar do cloreto de cálcio por via seca \\
\hline 9 & Análise elementar do cloreto de sódio por via seca \\
\hline 10 & Análise elementar do cloreto de cobre(I) por via seca \\
\hline 11 & Análise elementar do cloreto de cobre(II) por via seca \\
\hline 12 & Análise elementar do cloreto de lítio por via seca \\
\hline 13 & Análise elementar do cloreto de estrôncio por via seca \\
\hline 14 & Determinação da densidade e da densidade relativa de um sólido \\
\hline 15 & Determinação da densidade e da densidade relativa da água \\
\hline 16 & Determinação da densidade e da densidade relativa do etanol \\
\hline 17 & Determinação do ponto de ebulição da água \\
\hline 18 & Determinação do ponto de ebulição do etanol \\
\hline 19 & Determinação do ponto de fusão do enxofre \\
\hline 20 & Determinação do ponto de fusão do naftaleno \\
\hline 21 & Determinação do ponto de fusão do ácido salicílico \\
\hline 22 & Preparação de soluções \\
\hline 23 & Preparação de coloides por adição de uma solução saturada de acetato de cálcio a etanol absoluto \\
\hline 24 & Preparação de coloides por reação entre ácido clorídrico (concentrado) e solução diluída de tiossulfato de sódio. \\
\hline & $11^{\circ}$ ano \\
\hline $1-4$ & Identificar a presença de amoníaco e de compostos de amónio em materiais de uso comum - Teste A a D \\
\hline 5 & Síntese do sulfato de tetraaminocobre(II) monoidratado \\
\hline $6-9$ & Efeito da temperatura e da concentração na progressão global de uma reação \\
\hline $10-16$ & $\begin{array}{l}\text { Classificação de águas em ácidas, neutras ou alcalinas, utilizando como indicadores solução alcoólica de fenolftaleína, azul de } \\
\text { bromofenol, tornesol, carmim de índigo, universal, alaranjado de metilo e vermelho de metilo }\end{array}$ \\
\hline 17 & Classificação de águas em ácidas, neutras ou alcalinas, utilizando um medidor de pH eletrónico ou um sensor \\
\hline 18 & Apreciação do efeito da temperatura no pH de uma solução \\
\hline
\end{tabular}


- continuação -

\begin{tabular}{|c|c|}
\hline & 119 ano \\
\hline 19 & Verificar a variação do pH da água quando se faz borbulhar $\mathrm{CO}_{2}$ \\
\hline 20 & Verificar a variação do pH da água quando se faz borbulhar $\mathrm{SO}_{2}$ \\
\hline 21 & Força relativa do ácido clorídrico e concentração das soluções respetivas \\
\hline 22 & Força relativa do ácido nítrico e concentração das soluções respetivas \\
\hline 23 & Força relativa do ácido acético e concentração das soluções respetivas \\
\hline 24 & Titulação ácido forte - base forte utilizando solução alcoólica de fenolftaleína como indicador \\
\hline 25 & Titulação ácido forte - base forte utilizando vermelho de metilo como indicador \\
\hline 26 & Titulação ácido forte - base forte utilizando um medidor de pH eletrónico ou um sensor \\
\hline 27-38 & $\begin{array}{l}\text { Série eletroquímica Cu/Zn( }\left(\mathrm{NO}_{3}\right)_{2}(\mathrm{aq}) ; \mathrm{Al} / \mathrm{Zn}\left(\mathrm{NO}_{3}\right)_{2}(\mathrm{aq}) ; \mathrm{Mg} / \mathrm{Zn}\left(\mathrm{NO}_{3}\right)_{2}(\mathrm{aq}) ; \mathrm{Zn} / \mathrm{Cu}\left(\mathrm{NO}_{3}\right)_{2}(\mathrm{aq}) ; \mathrm{Al} / \mathrm{Cu}(\mathrm{NO})_{2}(\mathrm{aq}) ; \mathrm{Mg} / \mathrm{Cu}(\mathrm{NO})_{2}(\mathrm{aq}) \\
\mathrm{Mg} / \mathrm{Al}\left(\mathrm{NO}_{3}\right)_{3}(\mathrm{aq}) ; \mathrm{Cu} / \mathrm{Al}\left(\mathrm{NO}_{3}\right)_{3}(\mathrm{aq}) ; \mathrm{Zn} / \mathrm{Al}\left(\mathrm{NO}_{3}\right)_{3}(\mathrm{aq}) ; \mathrm{Cu} / \mathrm{Mg}\left(\mathrm{NO}_{3}\right)_{3}(\mathrm{aq}) ; \mathrm{Zn} / \mathrm{Mg}\left(\mathrm{NO}_{3}\right)_{2}(\mathrm{aq}) ; \mathrm{Al} / \mathrm{Mg}\left(\mathrm{NO}_{3}\right)_{2}(\mathrm{aq})\end{array}$ \\
\hline $39-45$ & Solubilidade do cloreto de sódio, cloreto de cálcio, carbonato de cálcio, iodo, heptano, hexano e etanol em água \\
\hline 46-51 & Solubilidade do cloreto de sódio, cloreto de cálcio, carbonato de cálcio, iodo, heptano e hexano em etanol \\
\hline $52-56$ & Solubilidade do cloreto de sódio, cloreto de cálcio, carbonato de cálcio, iodo e heptano em hexano \\
\hline 57 & Influência da temperatura na solubilidade do nitrato de potássio em água \\
\hline 58 & Avaliação da dureza de água dura preparada juntando cloreto de cálcio a água destilada \\
\hline 59 & Avaliação da dureza de água dura preparada juntando sulfato de magnésio a água destilada \\
\hline 60 & Avaliação da dureza de água destilada, usada como água macia \\
\hline 61 & Avaliação da dureza de água amaciada com carbonato de sódio (água dura preparada juntando cloreto de cálcio a água destilada) \\
\hline 62 & $\begin{array}{l}\text { Avaliação da dureza da água amaciada com carbonato de sódio (água dura preparada juntando sulfato de magnésio a água } \\
\text { destilada) }\end{array}$ \\
\hline
\end{tabular}

Tabela 4 - Matrizes SWOT para experiências 4, 10 e 11 do 10ㅇa ano

\begin{tabular}{|c|c|}
\hline \multicolumn{2}{|c|}{ Experiência 4 - Dessalinizar água do mar ou água salgada } \\
\hline $\begin{array}{l}\text { Pontos Fortes } \\
1 \text { - Risco baixo para a saúde devido às substâncias envolvidas } \\
2 \text { - Risco baixo para o ambiente devido às substâncias envolvidas } \\
\text { 3- Risco baixo de acidente devido às substâncias envolvidas } \\
4 \text { - Risco baixo de acidente devido ao equipamento } \\
6 \text { - Risco baixo de acidente devido à montagem } \\
7 \text { - Risco baixo de acidente devido a outros materiais vulgares de } \\
\quad \text { laboratório } \\
10 \text { - Não há utilização de outros solventes para além da água } \\
11 \text { - Utilização de materiais renováveis } \\
12 \text { - Utilização de materiais degradáveis a produtos inócuos } \\
14 \text { - Sem custos para os reagentes } \\
15 \text { - Sem custos de tratamento ou remoção de resíduos } \\
16 \text { - Só se utilizam materiais do quotidiano } \\
18 \text { - Relação com a química do mundo real } \\
19 \text { - Utilização de equipamentos (manta) }\end{array}$ & $\begin{array}{l}\text { Pontos Fracos } \\
8 \text { - Consumo elevado de água como solvente } \\
9 \text { - Consumo elevado de água como facilidade (refrigeração) } \\
13 \text { - É necessário aquecer (destilação) } \\
17 \text { - Sem relação com a química industrial } \\
20 \text { - Não se utiliza instrumentação }\end{array}$ \\
\hline $\begin{array}{l}\text { Oportunidades } \\
\text { - Pode ser realizada à microescala e utilizar-se uma coluna de ar para } \\
\text { a refrigeração } \\
\text { - Pode reutilizar-se a água de refrigeração }\end{array}$ & $\begin{array}{l}\text { Ameaças } \\
\text { - Imposição externa para reduzir consumos de água e de energia }\end{array}$ \\
\hline \multicolumn{2}{|c|}{ Experiências 10 e 11 - Análise elementar do $\mathrm{CuCl}$ e do $\mathrm{CuCl}_{2}$ por via seca } \\
\hline $\begin{array}{l}\text { Pontos Fortes } \\
1 \text { - Risco moderado para a saúde devido às substâncias envolvidas } \\
\text { (cloreto de cobre (I) e (II) - Xn) } \\
3 \text { - Risco moderado de acidente devido às substâncias envolvidas } \\
\text { (cloreto de cobre (I) e (II) - Xn) } \\
5 \text { - Risco baixo de acidente devido à instrumentação } \\
8 \text { - Sem consumo de água como solvente } \\
9 \text { - Sem consumo de água como facilidade } \\
10 \text { - Sem consumo de outros solventes } \\
20 \text { - Utiliza-se instrumentação (espectroscópio) }\end{array}$ & $\begin{array}{l}\text { Pontos Fracos } \\
2 \text { - Riscos elevados para o ambiente (cloreto de cobre (I) e (II) - N) } \\
7 \text { - Risco elevado de acidente devido a outros materiais vulgares de } \\
\quad \text { laboratório (utilização de gás) } \\
11 \text { - Não se utilizam materiais renováveis } \\
12 \text { - Não se utilizam materiais degradáveis a produtos inócuos } \\
13 \text { - É necessário aquecer } \\
14 \text { - Custo elevado de reagentes } \\
15 \text { - Custos de tratamento ou remoção de resíduos (cloreto de cobre (I) e } \\
\text { (II) - N) } \\
16 \text { - Não se utilizam materiais do quotidiano } \\
17 \text { - Sem relação com a química industrial } \\
18 \text { - Sem relação com outras situações da química do mundo real } \\
19 \text { - Não se utilizam equipamentos }\end{array}$ \\
\hline
\end{tabular}


- continuação -

\author{
Ameaças \\ - Imposição externa de maior segurança (bico de bunsen ou fogão \\ "camping gás" e cloreto de cobre (I) e (II) - N) \\ - Ausência de hottes suficientes nas escolas \\ - Verbas limitadas (para remoção de resíduos) \\ - Imposição externa para reduzir consumos de energia
}

Tabela 5 - Matrizes SWOT para experiências 1-4, 40 e 41 do 11ㅇano

Experiências 1-4 do 119 ano - Amoníaco e compostos de amónio em materiais de uso comum

\begin{tabular}{|c|c|}
\hline $\begin{array}{l}\text { Pontos Fortes } \\
7 \text { - Risco baixo de acidente devido a outros materiais vulgares de } \\
\text { laboratório } \\
8 \text { - Baixo consumo de água como solvente } \\
9 \text { - Sem consumo de água como facilidade } \\
10 \text { - Sem consumo de outros solventes } \\
13 \text { - Sem consumo energético } \\
16 \text { - Utilizam-se materiais do quotidiano para além da água }\end{array}$ & $\begin{array}{l}\text { Pontos Fracos } \\
1 \text { - Risco elevado para a saúde devido às substâncias envolvidas (Amoníaco } \\
\text { - T; reagente de Nessler - } \mathrm{T}^{+} \text {) } \\
2 \text { - Risco elevado para o ambiente devido às substâncias envolvidas } \\
\text { (Amoníaco - N; reagente de Nessler - N) } \\
3 \text { - Risco elevado de acidente devido às substâncias envolvidas (Amoníaco } \\
\text { - T; reagente de Nessler - } T^{+} \text {) } \\
11 \text { - Não se utilizam materiais renováveis para além da água } \\
12 \text { - Não se utilizam materiais degradáveis a produtos inócuos para além } \\
\text { da água } \\
14 \text { - Custo elevado de reagentes (reagente de Nessler) } \\
15 \text { - Custos de tratamento ou remoção de resíduos } \\
17 \text { - Sem relação com a química industrial } \\
18 \text { - Sem relação com outras situações da química do mundo real } \\
19 \text { - Não se utilizam equipamentos } \\
20 \text { - Não se utiliza instrumentação }\end{array}$ \\
\hline $\begin{array}{l}\text { Oportunidades } \\
\text { - Pode ser realizada à microescala e utilizar-se uma coluna de ar para } \\
\text { a refrigeração } \\
\text { - Pode reutilizar-se a água de refrigeração }\end{array}$ & $\begin{array}{l}\text { Ameaças } \\
\text { - Imposição externa de maior segurança (Amoníaco - T, N; reagente de } \\
\text { Nessler }-\mathrm{T}^{+}, \mathrm{N} \text { ) } \\
\text { - Ausência de hottes suficientes nas escolas } \\
\text { - Verbas limitadas (para remoção de resíduos) }\end{array}$ \\
\hline \multicolumn{2}{|c|}{ Experiências 40 e 41 do 119 ano - Solubilidade do cloreto de cálcio e do carbonato de cálcio em água } \\
\hline $\begin{array}{l}\text { Pontos Fortes } \\
1 \text { - Risco moderado para a saúde devido às substâncias envolvidas } \\
\text { (cloreto e carbonato de cálcio - Xi) } \\
2 \text { - Risco baixo para o ambiente devido às substâncias envolvidas } \\
3 \text { - Risco moderado de acidente devido às substâncias envolvidas } \\
\text { (cloreto e carbonato de cálcio - Xi) } \\
7 \text { - Risco baixo de acidente devido a outros materiais vulgares de } \\
\quad \text { laboratório } \\
8 \text { - Baixo consumo de água como solvente } \\
9 \text { - Sem consumo de água como facilidade } \\
10 \text { - Sem consumo de outros solventes } \\
12 \text { - Utiliza materiais degradáveis a produtos inócuos (cloreto e } \\
\text { carbonato de cálcio) } \\
13 \text { - Sem consumo energético } \\
14 \text { - Custo baixo de reagentes } \\
15 \text { - Sem custos de tratamento ou remoção de resíduos }\end{array}$ & $\begin{array}{l}\text { Pontos Fracos } \\
11 \text { - Não se utilizam materiais renováveis, para além da água } \\
16 \text { - Não se utilizam materiais do quotidiano, para além da água } \\
17 \text { - Sem relação com a química industrial } \\
18 \text { - Sem relação com a química do mundo real } \\
19 \text { - Não se utilizam equipamentos } \\
20 \text { - Não se utiliza instrumentação }\end{array}$ \\
\hline Oportunidades & Ameaças \\
\hline
\end{tabular}

Dessalinizar água do mar ou água salgada. Nesta experiência do $10^{\circ}$ ano (experiência 4, Tabela 3), água do mar ou água salgada é dessalinizada por destilação simples. O resultado da análise SWOT apresenta-se na Tabela 4. Nesta experiência só se utilizam materiais do quotidiano, de baixo custo, renováveis e degradáveis, não envolvendo riscos. Por outro lado, está relacionada com a química do mundo real e utilizam-se equipamentos. No entanto, como se realiza uma destilação, os consumos energético e de água são elevados. Atendendo a que podem ser realizadas à microescala, esses consumos podem reduzir-se porque os tempos de realização serão menores e porque, eventualmente, será possível substituir o condensador de Liebig por uma coluna de ar, não havendo então consumo de água. Pode também reutilizar-se a água de refrigeração, mas esta opção implica problemas operacionais que podem não ser fáceis de ultrapassar. Esta experiência apresenta $70 \%$ de pontos fortes do conjunto de pontos fortes possíveis (a dimensão de análise 5 , riscos de acidente devido à instrumentação, não foi avaliada, pois não se utiliza instrumentação), mas este valor pode 
aumentar se forem aproveitadas as oportunidades identificadas. Por estes resultados, esta experiência pode enquadrar-se num ensino CTSS.

Amoníaco e compostos de amónio em materiais de uso comum. Nestas experiências do $11^{\circ}$ ano (experiências 1-4, Tabela 3) identifica-se a presença de amoníaco e de compostos de amónio através de vários testes químicos específicos: pela formação de cloreto de amónio sólido na reação com cloreto de hidrogénio (experiência 1), pelo caráter alcalino de uma solução de amoníaco em água (experiência 2), por reação com o reagente de Nessler (experiência 3) e pela formação do ião complexo tetraaminocobre(II), de cor azul intensa (experiência 4). O resultado da análise SWOT apresenta-se na Tabela 5. Estas experiências envolvem riscos elevados para a saúde, ambiente e de acidente, não se utilizam substâncias renováveis, nem degradáveis, para além da água, apresentam custos de remoção de resíduos e o custo de um dos reagentes é elevado. Embora se utilizem alguns materiais do quotidiano, estão também envolvidos reagentes com riscos elevados e a sua realização exige a utilização de hotte, o que pode constituir uma dificuldade para a sua realização em contexto escolar. Não se utilizam equipamentos nem instrumentação e não se relacionam com a química industrial, apesar da importância da síntese do amoníaco nesta. Os consumos de água e de energia baixos são pontos fortes, mas a percentagem de pontos fortes é de $30 \%$ do conjunto de pontos fortes possíveis (as dimensões de análise 4-6, riscos de acidente devido ao equipamento, instrumentação e montagem, respetivamente, não foram avaliadas), não sendo adequadas a um ensino CTSS.

\section{Resultados}

Para esta avaliação começou-se por contabilizar os pontos fortes e fracos, as ameaças e as oportunidades, e as respetivas percentagens para todas as experiências dos $10^{\circ}$ e $11^{\circ}$ anos. Com base nesse dados foram construídos os gráficos da Figura 2, onde se apresentam os pontos fortes e fra- cos presentes em $60 \%$ ou mais das experiências, e a Tabela 6 , onde se apresenta o resumo das oportunidades e ameaças.

Esta análise possibilita uma avaliação das experiências em três vertentes: (i) uma avaliação de cada experiência, identificando os pontos fortes e fracos e pesando as ameaças e oportunidades, o que permite tomar decisões sobre o seu melhoramento ou abandono com base no paradigma CTSS (esta avaliação não será prosseguida aqui para não alongar o artigo, mas pode ser consultada em [13], que contém informação mais detalhada e completa sobre o presente trabalho e seus resultados); (ii) uma identificação global dos pontos fortes e fracos que estão presentes na maioria das experiências, o que dá uma visão dos aspetos em que parece ter havido mais intencionalidade no desenho das experiências num paradigma CTSS (pontos fortes) e onde houve menos intencionalidade (pontos fracos); e (iii) uma avaliação da frequência de pontos fortes e fracos presentes em cada experiência (para uma avaliação individual) ou no conjunto das experiências (para uma avaliação global), o que permite caracterizar a sua adequação individual ou global a um ensino CTSS, após definido um critério de exclusão com base em percentagens.

\section{Identificação de pontos fortes e} fracos. Numa perspetiva global, aparecem como pontos fortes, presentes em $60 \%$ ou mais da experiências: os consumos de água (dimensões 8-9) e de outros solventes (dimensão 10), em cada um dos anos; o consumo energético (dimensão 13), no $11^{\circ}$ ano, significando a realização de mais de $60 \%$ das experiências à temperatura ambiente; e o custo de reagentes (dimensão 14 ), no $10^{\circ}$ ano e no conjunto de ambos os anos.
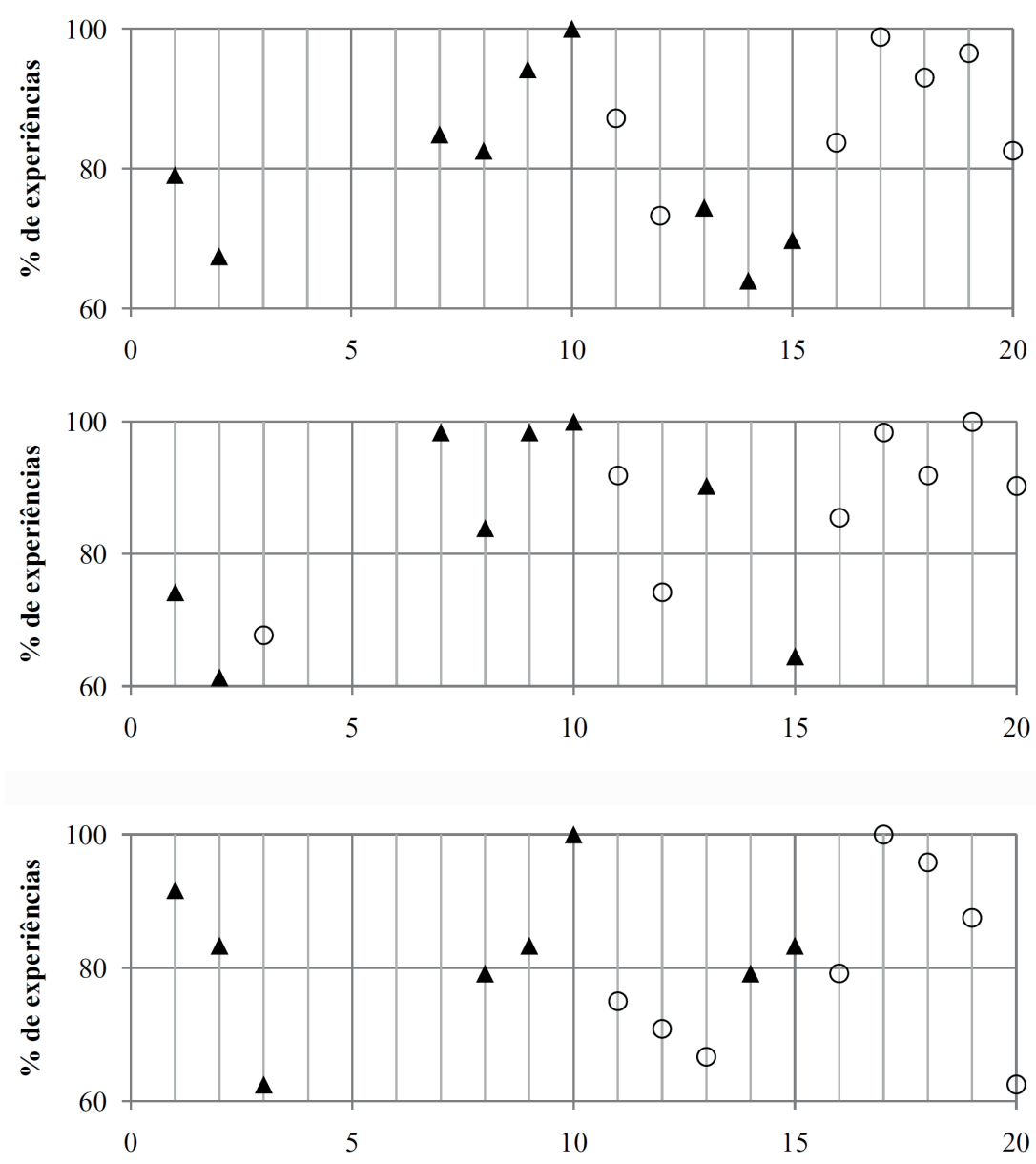

Dimensão de análise - ponto forte ou fraco

Figura 2 - Pontos fortes ( $\mathbf{\Delta}$ ) e pontos fracos (o) presentes em $60 \%$ ou mais das experiências dos

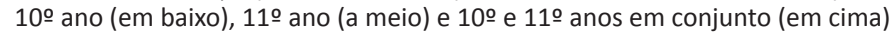


Tabela 6 - Resumo das oportunidades e ameaças para as experiências dos 10 e 11ํanos

\begin{tabular}{|c|c|c|c|c|c|c|}
\hline \multirow{3}{*}{ Dimensões de análise } & \multicolumn{6}{|c|}{ Oportunidades } \\
\hline & \multicolumn{2}{|l|}{$10 \%$ ano, $\mathrm{N}=24$} & \multicolumn{2}{|l|}{110 ano, $\mathrm{N}=62$} & \multicolumn{2}{|c|}{$\begin{array}{c}109,119 \\
N=86\end{array}$} \\
\hline & Experiências & $\begin{array}{c}\operatorname{Exp} \\
\%\end{array}$ & Experiências & $\begin{array}{c}\text { Exp } \\
\%\end{array}$ & $\begin{array}{l}\text { Exp } \\
\text { № }\end{array}$ & Exp \% \\
\hline Pode ser realizada à microescala & $1-5$ & 20,8 & 5 & 1,6 & 6 & 7,0 \\
\hline Pode reutilizar-se a água de refrigeração & $1,4-5$ & 12,5 & & 0,0 & 3 & 3,5 \\
\hline Pode utilizar-se coluna de ar para refrigeração & 1,4 & 8,3 & & 0,0 & 2 & 2,3 \\
\hline Dimensões de análise & \multicolumn{6}{|c|}{ Ameaças } \\
\hline Imposição externa de maior segurança & $2,3,6-13,16,18-20,23,24$ & 66,7 & $\begin{array}{l}1-10,14-16,19,20,24 \\
25,27-38,42-57\end{array}$ & 72,6 & 61 & 70,9 \\
\hline Ausência de hottes suficientes & $6-13$ & 33,3 & $1-9,20$ & 16,1 & 18 & 20,9 \\
\hline Verbas limitadas & $3,10,11,20$ & 16,7 & $\begin{array}{l}1-9,28,29,42,43,45 \\
49-56\end{array}$ & 33,9 & 25 & 29,1 \\
\hline Imposição externa para reduzir consumos de água & $1,4,5$ & 12,5 & & 0,0 & 3 & 3,5 \\
\hline Imposição externa para reduzir consumos de energia & $1,4-13,17-21$ & 66,7 & $5,6,18,57,61,62$ & 9,7 & 22 & 25,6 \\
\hline
\end{tabular}

Se considerarmos todos as dimensões que dizem respeito aos riscos, no seu conjunto, e que contribuem para a segurança ou a sua ausência, o que inclui os riscos para a saúde, ambiente e de acidente, devido às substâncias, e riscos de acidente devido ao equipamentos, instrumentação, montagens ou outros materiais vulgares de laboratório (dimensões $1-7$ ), verifica-se que 75 e $73 \%$ das experiências dos $10^{\circ}$ e $11^{\circ}$ anos, respetivamente, e $73 \%$ no conjunto das experiências de ambos os anos, apresentam pelo menos um desses riscos, embora alguns deles possam estar ausentes em mais de $60 \%$ das experiências, por exemplo os riscos para o ambiente (dimensão 2), que aparecem como pontos fortes.

Aparecem como pontos fracos, em mais de $60 \%$ das experiências de cada um dos anos: a utilização de substâncias renováveis e de substâncias degradáveis a produtos inócuos (a água não é contabilizada em ambos os casos) (dimensões 11 e 12, respetivamente); a utilização de materiais do quotidiano (a água não é contabilizada) (dimensão 16); a relação com a química industrial e outras situações do quotidiano (dimensões 17 e 18, respetivamente); e a utilização de equipamentos e instrumentação (dimensões 19 e 20, respetivamente). O consumo energético (dimensão 13) aparece como um ponto fraco para o $10^{\circ}$ ano, significando a necessidade de aquecimento em mais de $60 \%$ das experiências.

Frequência de pontos fortes e fracos. Considerando a percentagem de pontos fortes e fracos presentes, os resultados são resumidos nos gráficos da Figura 3 para o conjunto das experiências dos $10^{\circ}$ e $11^{\circ}$ anos. Pode concluir-se que $70 \%$ das experiências apresentam $50 \%$ ou menos de pontos fortes e $40 \%$ apresentam $50 \%$ ou mais de pontos fracos.

\section{DISCUSSÃO}

Em face do objetivo último do trabaIho, a discussão que se segue será

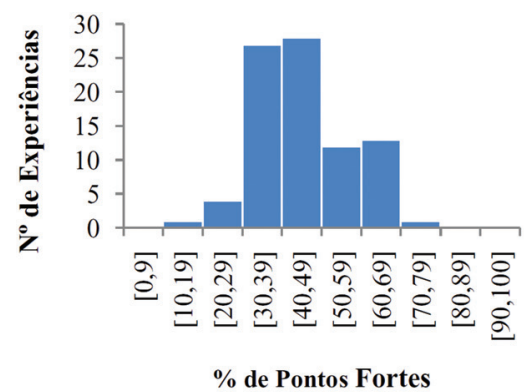

focada em cada uma das vertentes $T$ (Tecnologia), S (Sociedade) e S (Sustentabilidade), para tirar conclusões sobre a sua relevância nas experiências avaliadas. Os resultados indicam que as componentes Tecnologia e Sociedade, de acordo com os critérios estabelecidos, estão praticamente ausentes. No que se refere à Sustentabilidade, mais de $70 \%$ das experiências apresentam riscos, o que pode levar à necessidade de substituição de experiências, atendendo às ameaças identificadas, tais como a imposição externa de maior segurança ou a ausência de hottes suficientes nas escolas (os aspetos de segurança são importantes para a inclusão/exclusão das experiências num modelo CTSS). Pontos fortes identificados nesta vertente, tais como baixo consumo de água e de outros solventes, e a realização de

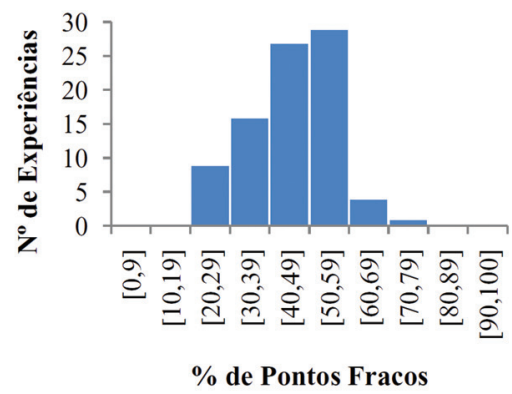

Figura 3 - Distribuição da frequência do conjunto das experiências dos 10 ㅇ e 11음 anos em função da \% de pontos fortes e fracos. Número total de experiências: 86 
experiências à temperatura ambiente, são aspetos positivos, que podem ser aumentados se forem tidas em conta as oportunidades identificadas (realização à microescala, substituição de condensadores de Liebig por colunas de ar ou reutilização da água de refrigeração utilizada nas destilações).

Em suma, poucas experiências envolvem materiais do quotidiano (para além da água), instrumentação, equipamentos, materiais renováveis e degradáveis a produtos inócuos, e se relacionam com a química do mundo real. Só uma experiência apresenta relação com a química industrial (experiência 5 , do $11^{\circ}$ ano), uma síntese em que o composto obtido tem aplicação real, aliás a única síntese proposta nos programas dos $10^{\circ}$ e $11^{\circ}$ anos. As experiências de síntese são adequadas a este tipo de ensino, particularmente se tiverem aplicação real na indústria, isto é, se os compostos forem produzidos industrialmente, pois colocam-se aspetos que excedem o habitual cálculo de rendimentos - aspetos químicos, tais como reação química, estequiometria, equilíbrio, cinética, energia, etc., bem como aspetos ambientalmente relevantes, como os de segurança, formação de resíduos, otimização da economia atómica e de verdura química. Pelas razões apontadas, as experiências de síntese contribuem frequentemente para uma abordagem ampla da química, num contexto industrial e societal, bem inserida numa opção CTSS para o ensino da Química - a sua quase absoluta ausência dos atuais programas do secundário [6] é extremamente lamentável. Mas, neste contexto, o desafio é propor sínteses que, ao mesmo tempo, envolvam riscos baixos, materiais renováveis, degradáveis e do quotidiano, e tenham aplicação real na indústria, o que não é fácil. Por outro lado, seria importante caracterizar o produto obtido em termos da sua pureza, por forma a utilizar-se instrumentação. É também de referir que as destilações implicam um elevado consumo de água, o que deve ser motivo de preocupação, sendo importante pensar-se na reutilização da água. $A$ adoção de uma proposta deste tipo, num enquadramento CTSS, como presentemente se impõe, exigirá a elaboração e desenho de novas experiências e profundas alterações dos programas atuais.

\section{Conclusões}

A utilização da análise SWOT na avaliação das atividades laboratoriais de Química do ensino secundário permitiu avaliar as atividades numa perspetiva CTSS, englobando na avaliação aspetos relacionados com a Tecnologia, Sociedade e Sustentabilidade. Num futuro, que se espera próximo, as atividades laboratoriais para o ensino da Química devem ser cuidadosamente escolhidas e desenhadas de forma a adequarem-se a um ensino CTSS e, por isso, espera-se que este artigo possa ser um contributo, ainda que modesto, para tornar essa opção mais próxima.

A análise SWOT permitirá outras avaliações, após definição de outras dimensões de análise, por exemplo, dirigidas aos objetivos definidos, às competências a desenvolver e à metodologia a utilizar na sala de aula para atingir os objetivos e promover o desenvolvimento das competências. Nestas últimas será de incluir as competências verdes, necessárias para atividades profissionais verdes, resultantes da introdução de práticas e tecnologias verdes, que merecem crescente atenção [14]. Por isso, a análise SWOT parece ser uma ferramenta com lato alcance no domínio da química e que merece continuar a ser explorada.

Em suma, o tipo de análise apresentado pode ser útil na avaliação, no desenho, ou no redesenho de atividades laboratoriais, tendo em vista a sua inserção num ensino da Química de cariz CTSS, essencial no presente contexto de luta societal pela Sustentabilidade, em que a inovação da tecnologia adquire um papel fulcral.

\section{REFERÊNCIAS}

[1] G. Aikenhead, What is STS science teaching?, in J. Solomon e G. Aiken- head (eds), STS Education - International Perspectives on Reform, TCP (1994), p. 47-59.

[2] E. Pedretti, J. Nazir, Currents in STSE education: Mapping a complex field, 40 years on, Sci. Educ. 95 (2011)601-626.

[3] A. Wals, Learning for a Sustainable World, UNESCO, 2009.

[4] L. Wong (ed), Globalization and Education for Sustainable Development Sustaining the future, UNESCO, 2005.

[5] A. A. S. C. Machado, Da Pobreza Química à Sustentabilidade e Química Verde, Química - Bol. S. P. Q. 114 (2009) 27-33.

[6] DGIDC Web: http://sitio.dgidc.minedu.pt/secundario/paginas/programas_es_f.aspx (Direção Geral de Inovação e Desenvolvimento Curricular, acedido em 23-02-2011).

[7] D. A. Costa, M. G. T. C. Ribeiro, A. A. S. C. Machado, Análise da Verdura das Actividades Laboratoriais do $10^{\circ}$ ano do Ensino Secundário, Química Bol. S. P. Q. 115 (2009) 41-49.

[8] D. A. Costa, M. G. T. C. Ribeiro, A. A. S. C. Machado, Análise da Verdura das Actividades Laboratoriais do $11^{\circ}$ ano do Ensino Secundário, Química Bol. S. P. Q. 123 (2011) 63-72.

[9] S. E. Jackson, A. Joshi, N. L. Erhardt, Recent Research on Team and Organizational Diversity: SWOT Analysis and Implications, J. Manage. 29 (2003) 801-830.

[10] M. Deetlefs, K. R. Seddon, Assessing the greenness of some typical laboratory ionic liquid preparations, Green Chem. 12 (2010) 17-30.

[11] G. Sin, S. W. H. Van Hulle, D. J. W. De Pauw, A. van Griensven, P. A. Vanrolleghem, A critical comparison of systematic calibration protocols for activated sludge models: A SWOT analysis, Water Res. 39 (2005) 2459-2474.

[12] B. S. Spector, Qualitative Research: Data Analysis Framework Generating Grounded Theory Applicable to the Crisis in Science Education, J. Res. Sci. Teach. 21 (1984) 459-467.

[13] D. A. Costa, Métricas de Avaliação da Química Verde - Aplicação no Ensino Secundário, Tese de Doutoramento, Departamento de Química, Faculdade de Ciências da Universidade do Porto, 2011.

[14] European Centre for the Development of Vocational Training (CEDEFOP), Skills for Green Jobs, European Synthesis Report, UE, 2010. 